\title{
The Normative Structure of the Ordinary
}

\section{Roberto Frega}

\section{OpenEdition}

\section{Journals}

Electronic version

URL: http://journals.openedition.org/ejpap/370

DOI: 10.4000/ejpap.370

ISSN: 2036-4091

\section{Publisher}

Associazione Pragma

\section{Electronic reference}

Roberto Frega, "The Normative Structure of the Ordinary », European Journal of Pragmatism and American Philosophy [Online], VII-1 | 2015, Online since 07 July 2015, connection on 02 May 2019. URL : http://journals.openedition.org/ejpap/370 ; DOI : 10.4000/ejpap.370

This text was automatically generated on 2 May 2019.

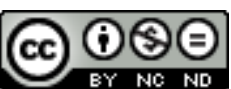

Author retains copyright and grants the European Journal of Pragmatism and American Philosophy right of first publication with the work simultaneously licensed under a Creative Commons AttributionNonCommercial-NoDerivatives 4.0 International License. 


\title{
The Normative Structure of the Ordinary
}

\author{
Roberto Frega
}

\section{Understanding the Normative}

1 Normativity is everywhere, and normative talk is a central dimension of social life from the ground level of everyday interaction to the more structured and institutionalized domain of social cooperation. Normativity refers to our capacity to discriminate between appropriate and non-appropriate responses to stimuli and to the capacity to critically appraise and revise the patterns that regulate those forms of conduct in which we express this sense of appropriateness. But it refers also to our capacity to act in accordance with such appraisals, and in particular to act in ways that address directly the normative orders which govern our lives.

2 As such, normativity is arguably the central object of practical philosophy (including moral, political, and legal theory), and according to the received view:

[s]omething is said by philosophers to have 'normativity' when it entails that some action, attitude or mental state of some other kind is justified, an action one ought to do or a state one ought to be in. (Darwall 2001) ${ }^{1}$

3 This definition encompasses in a classical way the main features philosophers assign to this concept, namely justificatory concern and rational content. Normativity is concerned with justifying (or it is that which justifies) a given course of action by referring to its rational content. Normativity has to do with the rational content of human action and its sources are to be found in human reason (Korsgaard 1996). From a different angle, it may be said that normativity has to do with the constraining power of norms (Brandom 1979), and with the accordance of actions to rules.

4 Applying norms, following rules, or complying with institutional imperatives have traditionally been conceived as the normative practices which define the core area of normativity. This explains why a consolidated tradition in philosophy ${ }^{2}$ has identified 
normativity with the 'ought,' that is to say, with the possibility of discriminating things as they are from things as they should be. Such discrimination is based upon the existence of criteria - which we call 'normative' - to which we refer when we claim something to be the right, legitimate, just, and appropriate way of doing things when what is at stake are ways of treating other human beings.

Normativity so conceived expresses itself in normative judgements, those concerning the appropriateness of discourses, actions, or institutions, and has, therefore, an irreducibly epistemic dimension, that is, normative talk needs legitimation, which in turn requires criteria for establishing the validity of normative claims. By extension, normativity deals with the discursive activities through which agents reclaim grounds of validity for their claims. In recent decades this mainstream idea has come under attack. Wittgensteinians and post-Wittgesteinians, neo-pragmatists, ethical particularists, liberal realists have all, in the various quarters of their research, put this received view on trial. These important criticisms notwithstanding, central intuitions concerning the priority of justificatory moves in normative theory, the possibility of uncoupling justification from application, the priority of the discursive, the relative autonomy of the normative from the empirical, remain tacitly accepted assumptions in philosophical ways of proceeding. Consequently, value, norm, and institution remain at the heart of our way of thinking about normativity, and their justification and/or critique continue to absorb the best of philosophy's energies.

6 In this paper I seek to challenge some of the basic assumptions which lie at the heart of this widespread, often taken for granted, picture of what normativity is in order to let emerge a different image of our relationship to the normative domain. ${ }^{3}$ This attempt will require, as I intend to show, a double theoretical move. On the one hand, we need to challenge received views concerning the intellectual division of labour between normative and empirical sciences. In particular, we need to challenge a view which construes normativity through its opposition to regularity, where the first is submitted to the logic of the 'ought,' while the second follows the empirical logic of facts. It is precisely in light of this view that one may feel entitled to state that philosophy is concerned with normativity (it states how things should be), while the social sciences are concerned with regularity (they describe how things are). On the other hand, we need to integrate into our view of normativity more empirical data about its mode of operation, its main constituents, its way of functioning, the main sites where we encounter it. We should in this sense take more seriously the theoretical consequences of what I have called "the empirical fact of normativity." This will force us to part with the habitual overintellectualization through which normativity is usually conceived of in philosophy, that is, considered as being mainly a fact of reason. Philosophical attempts to integrate empirical data into theories of normativity have been scant, and generally limited to this sui generis social practice which is linguistic practice. My general assumption is that often neglected sociological traditions loosely identifiable as 'social interactionists' provide an account of our constitution as normative creatures which is deeply at odds with standard philosophical accounts of normativity, so that taking these sociological accounts seriously requires in turn that we radically change our basic philosophical assumptions about normativity. ${ }^{4}$

7 To counter this received philosophical view of normativity, we need to inquire into the basic structure of ordinary experience. In particular, we need to look more carefully into those largely tacit, and difficult to perceive, aspects composing the 'order of interaction,' 
and it is with reference to this dimension of social life that I intend to speak of a normative structure of the ordinary. To uncover this neglected dimension of normativity, we can rely upon those sociological and philosophical traditions which, more than any other, have explored the normative resources of ordinary experience. These traditions - among which I will single out ethnomethodology, the philosophy of ordinary language, and pragmatism ${ }^{5}$ - have fashioned an image of human beings as normative creatures, an image which, if taken seriously, radically alters our most consolidated ideas about what normativity is and how it functions. This is, at any rate, the conclusion I intend to defend in this paper. The paper is divided into three parts. In the first I introduce ethnomethodology and Goffman's sociology and discuss their implications for the study of normativity. In the second I connect the findings of this sociological tradition with some implications of Austin's philosophy of ordinary language. Finally, in the third section I will contend that the pragmatist conception of normativity takes these empirical evidences adequately into account. Overall, my argument is that, while the sociological tradition of social interactionism shed new light on the "empirical fact of normativity," ordinary language philosophy and pragmatism offer a theoretical account of normativity which is consistent with the picture of normativity which emerges from these empirical descriptions.

\section{Normativity and the Constitutive Order of Everyday Interactions}

8 In the second half of the 20th century, an entire array of sociological approaches - in the forefront of which stand symbolic interactionism, ethnomethodology, conversation analysis, and the work of Ervin Goffman - have focused upon a till then neglected dimension of social reality, that of everyday forms of social interaction. Some of these works have gone to considerable lengths to explore the ordinary texture of social life, and in claiming social interaction to be its basic structure, it becomes the location at which the social bond is engendered and maintained, the space at which social order and cooperation are realized. If one takes this sociological view seriously, one is compelled to assume, at least hypothetically, that this dimension of social life has a decisive connection with what philosophers term 'normativity.' If, indeed, normativity has to do with how human beings orient their life and regulate their reciprocal interactions, and if the basis of social life has to be discovered in this neglected and "noticed but unseen" order of interaction, then it seems plausible to inquire into the normative implications of a view of society that claims the priority of the constitutive or interaction order over the "aggregative order" governed by the better known play of norms, values, and institutions. ${ }^{6}$ In this rich and complex sociological panorama, the works of Goffman and Harold Garfinkel stand out as the most compelling and it is to them that I now turn.

\section{Ethnomethodology and the Priority of the Social Order of Interaction}

9 Ethnomethodology has probably provided one, if not the most, interesting and empirically compelling series of arguments in support of a distributed and allencompassing conception of normativity. The novelty of the ethnomethodological revolution consists in having shown, in surprising discontinuities with previous sociological traditions, that the successful continuance of social life is not granted merely 
by the existence of shared values, norms, institutions, or attitudes, nor by the mere operating of social steering systems, but that it relies upon the incessant renewal of social order through the active and passive normative engagement of social members within the everyday ordinary interactions which structure our interpersonal intercourse. In so doing, ethnomethodology has challenged the most pervasive conception of social order as based upon collective orientations, of which paradigmatic examples can be found in Durkheim's idea of collective mentality as a shared set of normative expectations capable of granting social coordination. Contrary to mainstream sociological traditions, ethnomethodologists have shown that the ordered continuation of social life is achieved through the "ongoing accomplishment of the concerted activities of daily life" (Garfinkel 1967: vii). As such, it relies upon constantly renewed and continuously accomplished normative interactions aimed at confirming and adjusting our reciprocal normative expectations, and that only seldom take the shape of explicit and discursive acts. The point illustrated by ethnomethodology is that, without this active normative engagement, the social world simply falls apart and no collective undertaking can succeed. Ethnomethodologists have consequently insisted that normativity cannot be adequately grasped by the uncoupling and articulating of the justification of norms and their subsequent application, ${ }^{7}$ but that it relies upon the ongoing micro, often tacit and constantly produced, doing and undoing of normative acts that confirm, adjust, and repair the fragile net of our normative expectations.

10 Garfinkel's "breaching experiments" (Garfinkel 1967: esp. Chaps. 1 and 2) have shown beyond reasonable doubt not only that our ordinary life is structured by an implicit range of normative expectations, but that normativity is also constantly produced through active, albeit often tacit, normative actions accomplished by social members, such as those accomplished by social actors standing in line waiting for their turn to be served. According to Garfinkel (1967: 22):

[...] a society's members encounter and know the moral order as perceivedly normal courses of action - familiar scenes of everyday affairs, the world of daily life known in common with others and with others taken for granted.

11 The naturalness of these courses of action is itself an achievement of social interaction, something that social members generate by orienting their own and others' actions in accordance with their normative expectations. These actions, which take the form of turns in either conversational or action-based exchanges, often remain beneath the threshold of our perceptive attention, constituting what Garfinkel describes as the "seen but unnoticed" background upon which social life plays out. Among these actions stand a vast array of normative practices through which actors confirm or disconfirm, correct and amend, reinforce or downplay what is being advanced by their interlocutors. This "seen but unnoticed" background is not made up of stable values, norms or expectations, but of knowledge concerning the proper way of engaging in social interactions, and it consists of a plurality of ways of doing through which the mutual engagement of social members is kept on the track of 'proper' interaction.

According to Garfinkel, social order must be necessarily worked out in its details at the level of local interaction because normative orders are structurally and unavoidably under-determined. ${ }^{8}$ Hence the possibility of engaging successfully in a social interaction reposes upon our capacity to interpret the other's reaction with reference to the assumed regularity of a shared system of "perceived normal values" (Garfinkel 1967: 94) which enable us to fill the gaps produced by the indexical structure of social life. As Garfinkel 
constantly reminds us, these "perceived normal values" are not assumed by members once and for all, but are constantly produced and reproduced - Garfinkel says "managed" - in the course of the social interaction itself. The performative efficacy of our assumptions depends, then. upon its constant confirmation through the feedback of others. It is not assumed but rather constructed and entertained through the give and take of sequential turns within a social interaction. In other words, the very possibility of social interaction relies upon: "the enforceable character of actions in compliance with the expectancies of everyday life as a morality" (Garfinkel 1967: 53).

The order of interaction is then characterized by three distinctive features. The first is that social interaction heavily depends upon this duty to comply with expectations. The second feature is that this order is not given or found, but constantly produced through the interaction itself. The third feature is that these expectations find only weak transcendent guarantees outside the social situation itself. Indeed, it is a central thesis of social interactionist approaches that the interaction order does not find independent guarantee in some transcendent institution, but relies upon nothing more than 'what everyone knows.' Taken together, these three features concur to define the distinctive normative quality of the order of interaction, which is to say its structural fragility. Depending upon members' willingness to comply; being exposed to the inappropriateness of members' actions and lacking any independent normative source, the order of interaction is constantly exposed to the threat of its failure. This fact may explain why participation imposes upon all participants the duty of taking care of it, not only by complying with expectations, but also by forcing others to do so. These empirical facts render even the simplest settings of social life, such as standing in a queue or exchanging greetings with strangers in the street, literally imbued with normativity.

These empirical facts have, therefore, decisive implications for a theory of normativity. In fact, ethnomethodological findings show that, in taking decisions, society's members do not act as if they were following rules or applying previously agreed or shared systems of norms. On the contrary, detailed empirical studies of the normative logic of interaction orders show that the appropriateness of a normative order is something which is contextually decided according to the needs of the situation. Whereas in post-hoc explanations actors tend to describe their behavior according to a rule-following or norm-application model, ethnographic observation shows that, in reality, their decisions follow a different dynamic, as they are heavily dependent upon interactional sequences which define the social situation. A member of society will normally tend to take their decisions not according to a pre-ordained set of norms and values, but according to their actual (i.e. in that particular phase of the ongoing situation) understanding of what are the: "normatively valued social structures which the subject accept[s] as conditions that his decisions [...] had to satisfy" (Garfinkel 1967: 93). What the subject takes for accepted conditions is indeed the outcome of the interaction itself and depends upon a textured web of expectations, upon the capacity of members to adequately interpret the signs produced by other members, upon the reliability of their presuppositions concerning others' intentions and epistemic states. Interestingly enough, members' interpretive strategies tend in most cases to operate so as to confirm standard expectations and to preserve the conditions upon which the social interaction can be successfully pursued. The order of interaction is autonomous in the sense that, within it, subjects do not act according to pre-given normative orientations, but tend rather to adjust their normative orientation to their perception of what the situation requires. The point is that the 
successful pursuit of the normative interaction imposes upon society's members constraints concerning their normative orientations. If we take the ethnomethodological lesson seriously, it becomes impossible to explain away the normative implications of these constraints in terms of "social influence" or "weakness of the will." The point is, rather, that the kind of normative work which is being done within the interaction order is simply not accountable in terms of rule-following, norm-application, or institutional compliance. Indeed, the indexical dependence revealed by ethnomethodological enquiries is a necessary condition of the successful furtherance of social life, its socialstructural presupposition or, as I call it, the normative structure of the ordinary.

\section{Ervin Goffman and "Face Work" as a Normative Practice}

15 A second take on the idea of human beings as normative creatures can be found in Goffman's study of the normative order of social interaction. ${ }^{9}$ Goffman's entire sociology takes on the challenge that the deepest dynamics of social life - and of normativity with it - can be disclosed to us provided we turn our attention to: "the little interactions that are forgotten about as soon as they occur, into what serious students of society never collect, into the slop of social life" (Goffman 1971: 138). Goffman has written that: "the main principle of the ritual order is not justice but face" (1967: 44). By this, I take him to mean that the preservation and constant maintenance of normative orders is the primary normative concern within human interaction, that saving the face of the other so as to bring the present interaction to fulfillment, rather than abstract compliance with norms, is the regulative standard to which our normative interactions are attuned.

For Goffman, normative social orders rely upon the constant and successful achievement of everyday micro normative practices through which agents take responsibility not only for their 'face' but also for that of other agents by constantly correcting, sanctioning, criticizing, approving others' behaviors which impinge upon the stability of social interaction. The point of Goffman's analysis that is relevant for my understanding of normativity is the idea that a mutual engagement is needed for the preservation of normative orders. On the one hand, each agent is engaged in what Goffman calls "defensive strategies," through which they protect their face from potentially disruptive social situations. On the other, each agent is equally engaged, through what Goffman calls "protective strategies," in helping others to save their own face. What Goffman terms "Face work," to this extent, is not a self-centered and defensive procedure, but a cooperative task. Since their very start, social orders presuppose and rely upon mutual normative interactions because in any social intercourse each agent exposes their face, but depends upon others for its defense.

The mutuality of normative engagements seems to stem from this very basic fact of social life that acquires, therefore, a primary meaning. As Goffman remarks: "when the person commits a gaffe against himself, it is not he who has the license to forgive the event; only the others have that prerogative" (Goffman 1967: 33). This determines the fact that social life is built upon "a system of checks and balances" that can operate only on the basis of strict cooperation, as each participant relies and depends upon others to preserve his own face and has in turn responsibility for the face of others. Indeed:

[...] it seems to be a characteristic obligation of many social relationships that each of the members guarantees to support a given face for the other members in given situations. (Goffman 1967: 42) 
, for instance, the social work accomplished by a pe Goffman calls "cooling the mark out" (Goffman 1952), a practice by which a social actor who has constructed "a conception of himself which cannot be sustained" needs to be "cooled out," which is to say helped to save their face and escape the socially unsustainable situation in which they have fallen (or been thrown). Goffman shows that, in circumstances in which an agent happens to have "defined himself in a way which the social facts come to contradict," it is only through the help of another social actor that they will be able to find their way out.

The mark must therefore be supplied with a new set of apologies for himself, a new framework in which to see himself and judge himself. A process of redefining the self along defensible lines must be instigated and carried along; since the mark himself is frequently in too weakened a condition to do this, the cooler must initially do it for him. (Goffman 1952: 456)

This social function is so important that society has institutionalized it in professional roles such as psychotherapists, while institutions have been created to host those who have definitively lost face (asylums, 'hobo jungles,' old people's homes, etc. - see Goffman 1952: 463).

This mutual dependence, which is constitutive of social life and defines the rough ground of normativity, entails "involvement obligations," since the preservation of the normative order on which social life relies depends upon each member's complying with these normative expectations. As a consequence:

[...] when the individual intentionally or unintentionally breaks a rule of etiquette, others present may mobilize themselves to restore the ceremonial order, somewhat as they do when other types of social order are transgressed. (Goffman 1967: 114) ${ }^{10}$

21 Starting from its roots, social life presupposes, and can exist only, as long as each participant accepts the role of a critical controller with regard to the behavior of each agent in the face of tacitly shared normative assumptions: "the individual must not only maintain proper involvement himself but also act so as to ensure that others will maintain theirs" (Goffman 1967: 116). These attitudes of mutual involvement that Goffman calls 'face work' seem, therefore, to provide the most general paradigm of human attitudes towards normative orders. ${ }^{11}$

Another aspect of the normative structure of the ordinary which emerges from Goffman's work concerns the centrality of the reparative dimension of normativity. As Goffman remarks, whereas in the case of the macro social order punishment seems to be the overarching goal of normative devices, in the case of the interaction order the concern to restore a smooth interaction overrides that for normative attribution and punishment:

Since the guilt is small and the punishment smaller, there often will be less concern

- and admittedly so - to achieve proper attribution than to get traffic moving

again." (Goffman 1971: 108)

The ritual work described allows the participants to go on their way, if not with satisfaction that matters are closed, then at least with the right to act as if they feel that matters are closed and that ritual equilibrium has been restored. If any discontent remains within either party, presumably it will have to be expressed or exhibited at some other time. In other words, after the ritual work, the incident can be treated as though it were closed. "So the 'round' that has occurred is also a complete interchange" (Goffman 1971: 140). Ordinary social life is densely textured by moves aimed at anticipating (and excusing) possible violations of the standard order of interaction (excuses, apologies) and 
at accounting ex post for offenses. If public life can go on successfully and social interaction does not breakdown, it is thanks to such interaction. The order of interaction is a normative order at least as important as the macro social order made up of values, norms, and institutions. Without the constant intervention of these remedial activities, social life would fall into chaos.

The normative implications associated with this stated priority of the order of interaction are quite striking:

When a robbery is committed, no innocent party is likely to volunteer himself as the culprit; when an interactional offense occurs, everyone directly involved may be ready to assume guilt and to offer reparation. (Goffman 1971: 108)

As a consequence:

[...] in the realm of public order it is not obedience and disobedience that are central, but occasions that give rise to remedial work of various kinds. (Goffman 1971: 108)

What Goffman terms "remedial work" consists of forms of apology or account through which a putatively offending agent restores the broken interaction, either by assuming responsibility for the deed or explaining why he did what he did. In both cases, as Goffman explains, the normative standard of the interaction does not seem to be adequacy or truth but efficacy in accomplishing a ritual exchange whose goal is to preserve the face of the participants so as to enable the interaction to continue:

A remedial interchange, then, includes all the moves taken in regard to a virtual offense, and these usually, but not inevitably, will leave the participants in a position to act as if the issue can be dropped. (Goffman 1971: 120)

Throughout these passages, Goffman emphasizes a distinctive feature of most social interactionist approaches, which is to say their insistence upon the relative autonomy of social interaction as having its end in itself. Differently put, social interactions are undertaken for their own sake and follow a logic that can be purely immanent. Hence the replacement of justice - an external normative standard - with face as a purely immanent normative criteria.

Ethnomethodologists, conversational analysts, as well as Goffman (and Goffmanians) have extensively studied how a normative order can emerge and be preserved out of face-toface ordinary interactions in apparently irrelevant situations such as standing in a queue, meeting in an lift, exchanging words in a floor shop, and so on (Goffman 1983). They have shown that these social practices rely upon an intrinsic logic of organization, as members make a commitment to the orderliness of that practice which is independent of other external considerations. One of the overarching and possibly most interesting achievements of this sociological tradition consists in having singled out for empirical description a dimension of social normativity not directly ascribable to the functioning of formal institutions and norms. Under the expressions of constitutive practices (Garfinkel) and the interaction order (Goffman), these authors have shown that the successful furtherance of social order relies upon two distinct normative phenomena. On the one hand, there is the well-known and much studied normative order of explicit norms and institutions, whose main logic can be described in terms of rule-following, norm application, and institutional compliance. At this level, social order can be analyzed in terms of an agent's compliance with a normative order that is publicly and explicitly embodied in norms, values, and institutions. On the other hand, ethnomethodology contends that social interaction is characterized by a specific form of normative order 
which does not rely upon pre-existing, transcendent norms and institutions that agents are merely expected to apply or comply with, but which is deeply situational.

As I have shown, through empirical accounts of the interaction order provided by social interactionists, three conditions emerge as the defining features of the normative structure of the ordinary: (a) its irreducible and constitutive indexicality, (b) the mutuality of engagements as a basic feature of our normative commitments, and (c) the pervasiveness of reparative kinds of normative practices. Taken together, they account for the specific normative mix of immanence, fragility, and objectivity which characterizes it.

To recapitulate briefly: at (a), the normative order of interaction displays forms of social relation in which social intercourse is not ruled by shared agreements about values, norms, and institutions. Commitment to the enabling conventions of interaction is something that cannot be explained neither in terms of a radical situationism nor in those of a structural determination of action. Anne Rawls has notably insisted upon this feature of social interactionism, claiming that these sociologies have shown indexicality to be a constitutive and necessary condition of the maintenance of social life. Indeed, "indexicality addresses the need for commitment and reciprocity in social situations" (Rawls 1989: 162), because: "it is through the very indexicality of the talk that it becomes possible to establish and verify mutual understanding" (Rawls 1989: 162). Because taking turns in a social interaction presupposes having attended previous turns, this obliges participants to pay attention to the interaction and to remain involved in it. In this perspective, indexicality maximizes: "the necessary commitment to the conversational order itself because they can only be understood if strict attention to sequencing is achieved" (Rawls 1989: 163). Hence Rawls concludes that:

The ironic result of this position is that potential ambiguity ("indexicality"), which philosophers have assumed must be eliminated to achieve understanding, is not only a recurrent feature of ordinary conversation but, according to Sacks, conversationalists appear to maximize their use of indexicals. Instead of viewing this as irrational behavior, he argued that the maximization of indexicality might be the solution to problems of meaning and in fact one of the keys to social order. [...] He argues that conversationalists maximize the potential for ambiguity at each next instant so that participants will need more closely to commit themselves to the ground rules of interaction. (Rawls 1989: 164-165)

She continues:

Their interactional achievement requires a commitment to a degree of reciprocity of perspectives among participants in an interaction that in turn demands that specific sets of institutionalized values be at least partially set aside for the time being. Because the principles of organization are viewed as responses to the needs of self and discourse, they have no particular content, i.e., they have no objective beyond achieving interaction. They are not aimed at achieving external goals, maximizing efficiency, class interests, etc. One's commitment is to the discourse, to the achievement of sociality. (Rawls 1989: 166)

32 At (b), for both Garfinkel and Goffman, interdependence, reciprocity, mutual commitments are all names given to the basic fact of social life, which is the interactional interdependence of social actors as the anthropological condition on which social life is built. Seen from the perspective of the order of interaction, the social bond relies upon this fact of mutual dependence. This lack of autonomy in the construction and preservation of the self appears as the building block of social life. This moral commitment defines the normative structure of the ordinary as a form of joint 
responsibility which can be decomposed into two dimensions which need to be kept distinct and separate. On the one hand, reciprocal responsibility of social actors as the 'face' of each of them depends upon the willingness of the other to save it. On the other hand, each social actor's responsibility for the social order, as the fragility of the order of interaction, requires the constant involvement of social agents with it.

These forms of interdependence may be described in terms of a relation of 'care.' On the one hand, the face of the other needs to be taken care of because its preservation can be achieved only as a result of a shared commitment. On the other hand, the order of interaction needs to be taken care of because it is punctuated by incessant normative conflicts concerning the shared definition of the situation that is needed to successfully manage the interaction.

At (c), the phenomenology of the normative structure of the ordinary shows that the philosophical concern with justification and critique is out of tune with how social life functions. The empirical evidence uncovered by social interactionists shows that the most widely shared normative practices stem from a concern for maintaining, repairing, adjusting, 'taking care of' normative orders. The order of interaction is a normative order constantly exposed to the danger of its breach, constantly open to the contestation of its participants' definition, and constantly subject to the uncertainty of events. And at the same time, its preservation, which is necessary both for the constitution of the self's identity as well as for the ordered pursuit of social goals, relies upon the careful attention those involved in the relation devote to it, upon their responsiveness to the need for constant adjustment, upon their ability to perform reparative actions, upon the capacity to reframe the situation or acceptance of the re-framing of others. Care, reparation, maintenance, appear in this light to be the basic normative concerns upon which social life relies.

These three features describe an order of normativity which diverges in its inner logic from that which dominates what sociologists call the institutional order whereby explicit commitment to shared norms, values, and institutions organize social life. On the one hand, this normative order is characterized by an extreme fragility, which in its turn imposes upon participants an involvement obligation. The order of interaction needs to be taken care of because it is punctuated by incessant normative conflicts concerning the shared definition of the situation that is needed to successfully manage the interaction. It is a normative order constantly exposed to the threat of its breach, constantly open to the contestation of the definition to be adopted by the participants, and caught in the grip of the uncertainty of events. And at the same time, its preservation is necessary both for the constitution of the self's identity and for the ordered pursuit of social goals. Its preservation relies upon careful attention those involved devote to it, upon their responsiveness to the need for constant adjustment, upon their ability to perform reparative actions, upon the capacity to re-frame the situation or accept the re-framing performed by others. Care, reparation, maintenance appear in this light to be the basic normative concerns upon which social life relies. On the other hand, while contextually dependent upon locally determined social interactions, this normative order is at the same time grounded in the objective structure of these same interactions because interactional constraints are not purely situational but, on the contrary, they display regularities. Its grounds of objectivity differ, however, from those of the institutional order. Indeed, at the level of the interaction order there are no external means of social control, no shared normative institutions, no explicit norms and values upon which it can 
rely. Its situational constraints are of a different kind. Seen as a constitutive order of interaction, social order is mainly described as a form of self-regulating practice, whose regulative criteria tend to be embedded in the practice itself, governed by the overarching goal of its successful accomplishment, tacit rather than explicit, and heavily underspecified and context-dependent. According to this view, social order is not imposed upon social reality top-down, but rather emerges bottom-up through social interaction, as a property of social interactions themselves. Hence its fragility. The normative order of social life reposes, therefore, in the mutual engagements through which actors constantly negotiate their social positions, coordinate their action, define and redefine their selves, as well as the social situations in which they act. According to this conception of social life, the standard view of normativity as being mainly concerned with rule-following, norm-application, and institutional-compliance loses much of its relevance.

Although neither Garfinkel nor Goffman have developed a full-blown account of normativity, their empirical analysis of social life clearly points beyond standard philosophical accounts, and call for a different, practice-based, and society-centered account of normativity. These sociological enquiries into elementary forms of social order are of major philosophical importance for scholars interested in normative questions. If, in fact, our normative constitution is first and foremost defined by the priority of orders of interaction and of mutual accountability, what does this social fact tell us about the nature of normativity? Is the mainstream paradigm of rule-following, norm-application, and institutional compliance adequate to account for the normative texture of ordinary life? My claim is that it is not, and that in order to adequately account for the ordinary structure of normativity, we need a different philosophical theory of normativity, one that takes into fuller account the practice-based and society-centered structure of experience. As I intend to show, pragmatism possesses the theoretical resources for developing such a philosophical conception of normativity..$^{12}$ I suggest that we see pragmatism as having developed a theoretical account of normativity consistent with the account of social reality developed by the tradition of social interactionism.

But before introducing pragmatism, there follows a short detour through the normative implications of ordinary language philosophy which provides a useful conceptual intermediate step between the sociological explorations evoked above and the theoretical reflections developed henceforward.

\section{The Normative Power of the Ordinary}

Ordinary language philosophy is another topical place where decisive aspects relating to the normative structure of the ordinary have been uncovered. More than in Wittgenstein's remarks on language games and forms of life, it is, however, in John Austin's linguistic pragmatics that we find the most interesting contributions to such a theory. In several places Austin has contested received views of normativity, stigmatizing the philosophical overemphasis upon justification (Austin 1956: 126) and pointing out the normative importance of everyday practices such as excuses. Austin's work has decisively contributed to the displacement of three of the most persistent fetishes of philosophy truth, assertion, and justification. By relocating truth within a larger theory of linguistic validity based upon the concept of felicity, by relativizing the assertoric function of language, and by inscribing justification within a larger view of what normative practices 
are, Austin not only changes our view of language, but more radically our view of normativity, in several ways introducing the dimension of the ordinary into the heart of philosophy.

Austin's studies of the multiple ways in which communication can fail, giving way to "infelicitous" acts (Austin 1962: lects. 1 \& 2), reveal the fragility of ordinary interactions in ways that clearly resonate with Garfinkel and Goffman's analysis of the order of interaction. By pointing to the several ways in which communication can fail, Austin shows that "the natural successful act" (Austin 1956: 128) relies upon an extremely delicate equilibrium. Breakdowns, misfires, infelicities, clumsiness, abuses are but some of the terms employed by Austin to indicate how social interaction can 'go wrong,' pointing, therefore, to the extraordinary importance and the astonishing pervasiveness of the reparatory dimension of normativity. The ordinary has a normative structure and normativity has an ordinary structure precisely because the successful pursuit of social life relies upon constant engagement in normative practices aimed at repairing and adjusting the fragile texture of everyday interactions.

One may be tempted to reduce Austin's interest in failure as a methodological strategy to explore normality through a via negativa. This interpretation, somehow legitimated by Austin himself (see in particular Austin 1956: 132), does not, however, deliver the full import of the OLP approach to the study of normativity. To fully appreciate the philosophical relevance of Austin's analysis of failure for a theory of normativity, one should rather recognize that his enquiries into the dark side of linguistic interactions are driven by a genuine interest in the fragility of the social bond. The relevance of failure does not consist merely in its, so to speak, ancillary contribution to unveiling the logic of successful interaction. Rather, failures are a legitimate object of philosophical inquiry in their own right because they point to the vulnerability of the ordinary ${ }^{13}$ and to its central place in the normative structure of the ordinary. If we accept that "J.L. Austin's philosophy of ordinary language is founded on failures in linguistic acts" (Laugier 2012: 339), we come closer to perceiving in what sense the core of normativity for Austin lies in practices of maintenance and reparation of our normative commitment and undertaking, rather than on practices of assertion, justification, or critique.

The basic structure of normativity is revealed by failure because failure reveals in turn the structural vulnerability of the social order of interaction. It is because our normative commitments are fragile, fallible, and continuously exposed to failure that we need to pay constant attention to them, to invest huge amounts of energy in repairing the webs of our normative commitments. As normative creatures, we seem to be involved much more in reparation, maintenance, and adjustment than in justification or critique of existing orders. Not only do infelicities, excuses, and other cases of failure show the fragility of our normative undertaking, but they also show that the successful achievement of social order does not rely upon the repetitive application of norms that have been fixed once and for all. On the contrary, and in astonishing continuity with the sociological teaching of social interactionists, it rather reposes upon locally enacted practices of normative reparation and maintenance.

Notably, it is excuses that reveal the ever-present necessity of repairing the normative web of the ordinary every time it is broken by our infelicitous linguistic (or nonlinguistic) acts. It is because the possibility of failure and infelicity are ever-present as a constitutive possibility of our normative engagements that, according to Austin, excuses, rather than justifications reveal the basic structure of normativity. More than in 
justifying, or in criticizing, it is in pleading for excuses that we reveal our nature as normative creatures. The incredibly rich variety of excuses reveals the incredibly rich variety of ways in which our normative engagements can falter, and in that way it reveals the extremely vast and complex array of reparative and maintenance practices which are required in order to make social order possible and effective. It is the vulnerability of the social order, rather than that of the individual personality, that is relevant here. The constant and ever- present possibility of failure evokes the responsibility of social actors for the success of social interactions. It is because we are always on the verge of failing our normative practices that we should, as normative agents, be constantly involved in the process of actively taking care of them. It is not the application or the following of the norm that define the basic structure of normativity, but rather its constant adjustment and reparation. The reference to adjustment and maintenance implicitly evokes the irreducibly social dimension of normative practices. It is always with reference to a social context, to the anticipation of the possible answer of my interlocutor, to the intersubjective dimension which constitutes normativity, that a linguistic - and a nonlinguistic - act may be felicitous or infelicitous.

43 It is this element of mutual responsibility and active and reciprocal normative engagement that emerges at the heart of our normative constitution.

\section{Pragmatism and the Project of a Society-Centered and Practice-Based Conception of Normativity}

Affinities between interactionist sociologies and pragmatism has often been noticed, although the discussion has mostly been confined to the theory of action and social theory. In this part of the paper I will not be concerned with direct influences between these movements or with real affinities. ${ }^{14}$ I will rather try to follow at some length the hypothesis that some general intuitions about normativity developed within the pragmatist tradition are not only consistent with the view of social life developed by interactionist sociologies, but, more radically, that a pragmatist-based conception of normativity provides the philosophical account most consistent with the view of social life which emerges out of these sociological approaches.

Pragmatists, starting at least from Peirce and Dewey, have emphasized the continuity between the tacit and non-tacit dimensions of experience, and have explored the naturalistic and social grounds of normativity. For Dewey 'morality is social,' and our normative stance is rooted in our natural and social constitution. In addition, pragmatism suggests that we understand the sources of normativity as lying within social experience, in the ongoing and context-bound struggles within problematic situations. Another distinctive feature of pragmatism is that it conceives of normative sources as fallible and experimental: arguments and experiences to be mobilized within contextualized processes of enquiry. According to this view, normative sources do not possess any intrinsic normative force. They are merely potential bases for action, whose validity must be established by those involved in the problematic situation at hand. Whilst pragmatist philosophers certainly did not achieve the sociological finesse involved in ethnomethodology's descriptions of social reality, Dewey's conception of the transactional nature of social life provides a valid theoretical framework for these and similar empirical researches. 
My intended reading of a pragmatist approach to normativity may appear to be at odds, or at least at variance, with the interpretation of pragmatism which has been predominant in the last two decades. It has indeed become customary to identify the pragmatist approach to normativity with its conception of habits, often coupled with a theory of creativity. ${ }^{15}$ In this now standard approach, normativity is understood as a chapter in the theory of action. Although this approach deserves all the interest it has received, it does not appear to be the best place to start if one wishes to account for facts about normativity highlighted in the previous sections. There is, however, another lesson we can draw from the pragmatist tradition from Peirce to Robert Brandom. This lesson, while not contradicting the previous one, adds further elements as it emphasizes the practice-based and society-centered structure of normativity. In Dewey's terms, it states that the structure of our normative commitments is irreducibly transactional. It not only rooted in the social context which constitutes the action-situation, but also constituted through face-to-face interaction and the transactional relationship integrating the organismic agent and their social and natural environment. In Mead's terms, it states that the basis of social life is provided by the social interaction through which the self is constituted. Contemporary pragmatist scholars as diverse as Brandom and Frederick L. Will have further articulated these basic intuitions, taking this seminal pragmatist intuition about normativity a step further. It is to these last two contributions which I now turn.

\section{The Inferential Texture of Social Normativity}

47 The first pragmatist take on normativity I propose to consider may surprise the reader, as it implies a privilege of the linguistic dimension which is, frankly, at odds with the practice-based programme developed so far. I refer to Robert Brandom's conception of normativity, and in particular to his idea of reasons as inferentially articulated commitments, and of action as receiving its intelligibility from the inferential network of reasons through which we account for it. As is known, Brandom's whole conception of language relies upon a normative fact, that is to say the normative fact of commitment. However, Brandom sees normativity as a basic and irreducible dimension of the human constitution, and this explains the relevance of his approach for what is pursued here. His whole semantic theory is built upon the intuition that, if the meaning of doxastic commitments in general ${ }^{16}$ derives from their deontic status within discourse, then normativity is implied in the basic structure of meaning and language. If we take Brandom's normative semantic seriously, its main normative implication is that the very possibility of mutual understanding - and therefore of the social intercourse that communication makes possible - depends upon the human capacity to endorse normative commitments. Indeed, the possibility of meaningful expression relies upon what Brandom calls 'scorekeeping,' which is the capacity to be accountable and to assume that others are accountable for the inferential implications of what they say.

Relationality and interaction are then built into the basic fabric of social life in a double sense. To begin with, as inference is in itself dynamic and relational. As is known, an inferential semantic is a semantic that defines terms through their relations to other terms which are logically related to them by way of what Brandom terms 'commitments and entitlements.' Secondly, by taking a normative stance, agents commit themselves inferentially to the valid assumptions that compose the social space of reasons. As 
Brandom explains: "The significance of being committed to a certain claim or assertible content is normative. It has to do with what else one is committed or entitled to" (Brandom 1994: 260). To put it otherwise, the normative implication of this conception of language and understanding is that our linguistic capacities presuppose and rely upon a normative nature, upon the capacity to assume and maintain in the face of others' commitments to what we say and do, and that this normative nature is from the beginning inter-subjective.

49 A second consequence of Brandom's inferentialism for my understanding of normativity is that if the meaning of the reasons for action (practical commitments) derives from their deontic status within a normative social practice, the meaning of actions undertaken in the light of reasons so constituted derives from these reasons' deontic status within a given normative social practice in which other scorekeepers deal with these reasons according to the game of deontic scorekeeping. The upshot of this point is that there is no intelligibility of action without the capacity to perceive inferential commitments, and to understand how other agents - scorekeepers - stand with respect to the inferential commitments that relate to a given reason for action. Therefore:

While the content of a practical commitment is thus partly specified in terms of the normative pragmatic significance of the beliefs or claims (about rain, cruelty, etc.) included in inferences which articulate part of the content of the commitment, it is also specified by patterns of normative propriety that directly concern what we ought and ought not to do to make that commitment true. (Levine 2012: 5)

To understand someone's discourses and actions means grasping what they commit themselves to, that is to say, what is right or wrong, appropriate or inappropriate for them to say and to do. It means treating them as being committed or entitled to given reasons or actions, which is to say, to treat them as a normative creature.

Whilst Brandom's reduction of experience to language stands in the way of any practicebased and society-centered approach like that which concerns me here, his understanding of normative commitments is nevertheless an important achievement for showing the pervasiveness of normative engagements at all levels of social life. In this sense, we should see Brandom's scorekeepers as truly normative creatures, in the sense made clear by Garfinkel's and Goffman's accounts of the dynamic interplay which textures the social order of interaction.

\section{Normativity-as-Governance}

52 A second take on the idea of normativity as practice within the pragmatist tradition is offered by the practice-based normative theory of Frederick L. Will, particularly his conception of normativity as "rational governance of practices," with its paired distinction between governance of practice and governance in practice. ${ }^{17}$ According to Will, governance is the main function accomplished by norms, and rational governance is one of the ways through which governance is produced. Will's distinction between what he calls governance in practice and governance of practice highlights the essential continuity between reflexive and non-reflexive dimensions of normativity. On the one hand, governance in practice refers to normative practices that preside over the regulated functioning of a given practice and that are operated by the controlled application and use of existing standards and criteria. Governance in practice reflects the fact that "governance is integral to the practices themselves" (Will 1981: 70-1), that a practice is by definition a normatively organized type of order, so that the existence of 
normative criteria is a constituent part of practices themselves. But it refers, as well, to the feedback effects that the functioning of a normative order produce upon the order itself, bringing about constant change and adjustment according to the needs of action. On the other hand, governance of practice refers to forms of governance which are more directly related to the reflexive dimension of practices. It denotes these normative practices by which a normative order is directly addressed. It encompasses: "those processes by which the relations of coordination utilized in the governance of action are instituted, annulled, or altered" (Will 1981: 71). Will sees normativity- as-governance as a distributed feature of social life. Human beings are normative through and through, and normative regulation is a mark of any social practice.

The idea that Will wishes to convey through this distinction is that, as the central category of normative theory, governance has priority over rationality. This stands in contrast to most normative theories, which prioritize rational justification, regarded as the quintessential normative practice, trumping any other practice having normative import. Whereas Will understands rational justification as but one among plural forms of governance, all having the same goal, which is the production of regulatory effects.

Will uses the substantive form 'governance' rather than the verbal form 'governing' more suggestive of direct action, because he believes that a central aspect of normativity - and one of the most neglected - is the priority of maintenance and adjustment over justification and critique. Most governance activities tacitly unfold in the background, without much notice, as activities serving stabilizing and regulative functions. They usually go unnoticed unless something 'goes wrong,' that is, unless something occurs that interrupts the regular functioning of a normative order or, even more disconcertingly, entire areas of normative activity within the order become dysfunctional.

Will believes that normative orders arise out of the basic need for human communities to stabilize their life in common. To this end, they develop structured patterns, a deep web of interlocking forms of adjustment activities and regularity having an eminently normative function that yields small but constant revisionary consequences in the order it-self. It is through this flow of tiny but regular adjustments that the order generally preserves its legitimacy.

In other words, Will is highlighting that norms and governance alike mostly function as 'regular upkeep' (the mostly tacit, mostly habitual and time-tested practice of tending to the system), rather than being concerned with instituting new norms or justifying them from scratch. Examples of regular, workaday activities of rational governance include: "generation, criticism, refinements, reconstruction, maintenance, reinforcement, and elimination" (Will 1988: 43). Normativity in the broad sense just described (as tacit upkeep) encompasses every aspect of human life. Norms tacitly govern the whole of our experience, and governance is all-embracing. That is why Will argues that normative reflection is an activity mostly concerned with adjustment and repair, unfolding in the interstices, as it were, in the manifold connections between the need for action and the answers or action worked out in response to such needs.

\section{Conclusion}

57 We can identify at least four main themes running through the three intellectual traditions I have sketchily evoked: (a) the acknowledgment of the importance of tacit 
presuppositions in the unfolding of social practices; (b) the priority assigned to interaction or transaction as the central dimension of social life, and (c) the priority of mutual dependence in the structuring of social order. Taken together, these themes give shape to the idea of normativity as a shared and distributed property of the ordinary. The historical references evoked in this paper show that none of these themes is really new. Whilst the focus on tacit presuppositions has been a common feature of a large array of 20th century philosophies, and whilst social interaction has similarly been reclaimed by a large spectrum of social theories, the third and the fourth theme have certainly been less intensively exploited - at least in philosophy. But the major philosophical value this project has to offer emerges from the joint consideration of these four conceptual factors and from the consequent adoption of an interdisciplinary strategy which this consideration requires.

What then do all these approaches have in common? Indeed, each of them articulates, in its own manner, the idea that normativity is embedded within everyday life as one of its constitutive and irreducible traits. They articulate the idea that the human being is a normative creature in the sense that a critical capacity for justification, critique, and other normative practices is a necessary ingredient of our human constitution. An attitude toward accountability is built into the fabric of social life as a necessary precondition for the success of any form of social intercourse, from the most simple forms of social interaction to the most complex forms of institutional normative governance. In this sense, the sources of normativity seem to lie in sociality rather than in reason. Normativity is, so to speak, not only deeply social - a fact few would contest today - but deeply embedded in the structure of ordinary life.

Consistent with this practice-based and society-centered approach, the sociological and philosophical traditions I have evoked converge in showing that the central function of normative practices is the maintenance, adjustment and reparation of normative orders in the face of local challenges. If we accept the general traits of this still incomplete account of the normative creature, we can find a way out of some of the recent difficulties in moral and political philosophy. A pragmatic approach based upon a widened understanding of normativity can provide theoretically fruitful tools for setting up a new agenda for understanding normativity. This approach (a) privileges the social over the individual as the primary source of normativity (society-centered approach), (b) acknowledges the normatively binding force of practices (practice-based approach), and (c) relies upon empirical evidence to explain the functioning of normative practices in ways much more sustained than have been done so far (multidisciplinary approach).

Five conceptual traits mark the practice-based and society-centered approach. The first is a focus upon the interplay of norms and actions which provides the methodological and conceptual framework for a multidisciplinary approach engaging human and social sciences and philosophy on a non-reductionist basis. The second is the adoption of the perspective of the situated agent in normative theory which is necessary to overcome the shortcomings of reductive (individualistic) accounts. The third is the definition of normative practices through reference to their regulative function in the dynamic interplay of agents with environments. The fourth is that norms and values are defined in accordance with a fallibilistic and experimental epistemology. The fifth is the priority assigned to empirical over conceptual analysis and to the history of social processes over the history of ideas in processes of critique and justification. The sixth is the priority of non-ideal theory over ideal theory. 
61 All these assumptions, which will have to be worked out in greater detail, point toward an understanding of normativity that is consistent with our grasp of ourselves as normative creatures and that satisfies the epistemic requirements of a theory of normativity.

\section{BIBLIOGRAPHY}

AUSTIN J., (1961 [1956]), A Plea for Excuses, in Philosophical Papers, Oxford, Oxford University Press, 175-204.

AUSTIN J., (1962), How to do Things with Words, Oxford, Clarendon University Press.

BRANDOM R., (1979), “Freedom and Constraint by Norms," American Philosophical Quarterly, 16, 3, 187-96.

BRANDOM R., (1994), Making it Explicit, Cambridge, Harvard University Press.

CAMIC C. (1986), “The Matter of Habit,” American Journal of Sociology, 1039-87.

CEFAI D., (2013), "L'ordre public micropolitique de Goffman," in E. Goffman, Comment se conduire dans les lieux publics. Notes sur l'organisation sociale des rassemblements, Paris, Economica, 209-90.

Collins R., (1989), “Toward a Neo-Meadian Sociology of Mind,” Symbolic Interaction, 12, 1, 1-32.

DARWALL S., (2001), Normativity, in E. Craig (ed.), Routledge Encyclopedia of Philosophy, London, Routledge.

DEWEY J., (1922), Human Nature and Conduct, in The Middle Works, 1899-1924, vol. 14, Carbondale, Southern Illinois University Press.

DORF M. \& C. SABEL, (1998), “Constitution of Democratic Experimentalism,” Columbia Law Review, $98,2,267$.

DUPRET B., (2011), Adjudication in Action: An Ethnomethodology of Law, Morality and Justice, Ashgate, Darmouth ("Directions in Ethnomethodology and Conversation Analysis Series").

DURKHEIM É., (1994 [1912]), Les formes élémentaires de la vie religieuse, Paris, PUF.

EMIRBAYER M. \& D. MAYNARD (2010), “Pragmatism and Ethnomethodology," Qualitative Sociology, 34, 1, 221-61.

FREGA R., (2012), Practice, Judgment, and the Challenge of Moral and Political Disagreement. A Pragmatist Account, Lanham, Lexington.

FREGA R., (2013), “The Practice-Based Approach to Normativity of Frederick Will," Transactions of the C. S. Peirce Society, 48, 4, 483-511.

FREGA R., (2014), “The Normative Creature: Toward a Practice-Based Account of Normativity," Social Theory and Practice, 40, 1.

GAMSON W. A. (1985), “Goffman's legacy to political sociology," Theory and Society, 14, 5, 605-22. GARFINKEL H., (1967), Studies in Ethomethodology, Englewood Cliffs, N. J., Prentice-Hall. 
GARFINKEL H., (2002), Ethnomethodology's Program: Working out Durkeim's Aphorism. Legacies of Social Thought, Rowman \& Littlefield Publishers.

GAUS G. F., (1996), Justificatory Liberalism, Oxford, Oxford University Press.

GIDDENS A., (1984), The Constitution of Society, Cambridge, Polity Press.

GoffMAn E., (1952), “On Cooling the Mark Out," Psychiatry: Journal of Interpersonal Relations, 5, 4, 451-63.

GOFFMAN E., (1967), Interaction Rituals, New York, Pantheon Books.

GoffMAn E., (1971), Relations in Public: Microstudies of the Public Order, New York, Basic Books.

GoffMAN E., (1983), “The Interaction Order,” American Sociological Review 48, 1-17.

HABERMAS J., (1987), The Theory of Communicative Action 2, Boston, Beacon Press.

HABERMAS J., (1993), Justification and Application, Boston, MIT Press.

HARTMANN M. \& A. HONNETH, (2006), “Paradoxes of Capitalism,” Constellations, 13, 1, 41-58.

HONNETH A., (2009), Pathologies of Reason: On the Legacy of Critical Theory, New York, Columbia University Press.

HONNETH A., (2010), The Pathologies of Individual Freedom: Hegel's Social Theory, Princeton, Princeton University Press.

HONNETH A., (2011), “On Markets and Morals,” Divinatio 33, 39-56.

HORKHEIMER M., (2002), “Traditional and Critical Theory," in Critical Theory. Selected Essays, New York, Continuum International Publishing Group.

KITCHER P., (2011), Science in A Democratic Society, Amherst, Prometheus Book.

KORBUT P., (2014), “The Idea of Constitutive Order in Ethnomethodology," European Journal of Social Theory, 17, 4, 479-96.

KORSGAARD C., (1996), The Sources of Normativity, Cambridge, Cambridge University Press.

LAKoff G. \& M. JOHNSON, (1981), Metaphors We Live By, Chicago, University of Chicago Press.

LAUGIER S. (2009), "Perdre ses concepts: sens commun, sens moral, sens social," in C. Gautier \& S. Laugier (eds.), Normativité du sens commun, Paris, PUF.

LAUGIER S. (2012), « La vulnérabilité de l'ordinaire goffman lecteur d'austin », in D. Cefaï \& L. Perreau (eds.), Erwing Goffman et l'ordre de l'interaction, p. 341-71, Paris, CEMS-CURAPP, EHESSUniv. D’Amiens.

LEVINE S., (2012), "Norms and Habits: Brandom on the Sociality of Action," European Journal of Philosophy, 21, 2.

LUMSDEN S., (2008), "Habit, Reason, and the Limits of Normativity," Substance, 37, 3, 188-206.

Quéré L. (2011), “Ways of Social Externalism: Pragmatism and Ethnomethodology,” European Journal of Pragmatism and American Philosophy, 3 (2), 148-166.

RAWLS A., (1989), "Language, Self, and Social Order: A Reformulation of Goffman and Sacks," Human Studies, 12, 1, 147-72.

Rawls A. (2009), “An Essay on Two Conceptions of Social Order: Constitutive Orders of Action, Objects and Identities vs Aggregated Orders of Individual Action," Journal of Classical Sociology, 9, 4, 500-20. 
RAWLS A., (2010), “Social Order as Moral Order ," in S. Hitlin \& S. Vaisey (eds.), Handbooks of Sociology and Social Research, New York, Springer.

RAWLS J. (1955), “Two Concepts of Rules,” The Philosophical Review, 64, 1, 3-32.

RAWLS J., (2001 [1997]), “The Idea of Public Reason Revisited,” in J. Rawls, The Law of Peoples, Harvard, Harvard University Press.

ROUSE J., (2007), “Social Practices and Normativity," Philosophy of the Social Sciences, 37, 1, 37-46.

SCHATZKI T. R., (1996), Social Practices. A Wittgensteinien Approach to Human Activity and the Social, Cambridge, Cambridge University Press.

SCHATZKI T. R., KNORR-CETINA K., VON SAVIGNY E. \& K. K. CETINA, (2001), The Practice Turn in Contemporary Theory, London, Routledge.

SCHUBERT H.-J. (2011), “Jenseits von Gemeinschaft and Gesellschaft: Prozesse der Differenzierung und Individuierung an Sicht der Chicago School of Sociology," in M. u. K. W. Hollstein, Bettina und Jung (eds.), Handlung und Erfahrung, Frankfurt, Campus Verlag p. 131-49.

SMITH S., (1987), “Hegel's Idea of a Critical Theory," Political Theory, 15, 1, 99-126.

Sullivan S., (2000), "Reconfiguring Gender with John Dewey: Habit, Bodies, and Cultural Change," Hypatia, 15, 1.

SULLIVAN S., (2006), Revealing Whiteness, Bloomington, Indiana University Press.

TURNER S., (2010), Explaining the Normative, Cambridge, Polity Press.

WILl F., (1981), “The Rational Governance of Practice," The American Philosophical Quarterly, 18, 3, 191-201.

WILL F., (1997), Pragmatism and Realism, Lanham, Rowman \& Littlefield.

\section{NOTES}

1. In the restricted sense in which I will discuss normativity, it refers to the regulation of conduct. Therefore, I will be concerned neither with epistemic nor with semantic normativity. Epistemic normativity has to do with the conditions of validity of assertions dealing with states of affairs, whereas semantic normativity deals with the conditions for the correct and incorrect use of linguistic expressions. Practical normativity deals with the ways in which we treat ourselves and - especially - other human beings, and, by extension, what belongs to them, what expresses their identity.

2. See Korsgaard 1996; Turner 2010; Rouse 2007; Brandom 1994.

3. My argument differs from that of Anne Rawls with which it only bears superficial resemblance. Whilst I am interested too in a rapprochement between philosophy and the social sciences in the study of normative issues, and whilst some of the authors we mobilize are the same, my argument does not build upon the distinction between constitutive and aggregate social order and, symmetrically, has no use for John Rawls' distinction between two concepts of rules (Rawls 1955), on which A. Rawls' argument is built. For a complete discussion of this point, see Rawls 2009 and issue 9, 4, 2009 of the Journal of Classical Sociology, edited by A. Rawls and entirely devoted to this theme.

4. This paper expands a practice-based approach to normativity whose general framework I have developed elsewhere. See in particular Frega 2014. 
5. For an overview of a pragmatist account of normativity which emphasizes the resources of this tradition's founders, see Frega 2012.

6. For a sociological account of this distinction, see Rawls 2009 and Korbut 2014.

7. A conception still alive in Habermas's conception of normativity. See notably Habermas 1993.

8. According to Garfinkel, social situations: "are, in any calculable sense, unknown; in their actual and intended logical structures are essentially vague; and are modified, elaborated, extended, if not indeed created, by the fact and manner of being addressed" (Garfinkel 1967: 96). It is this structural under-determination which imposes stringent normative expectations upon members' behaviour.

9. A detailed analysis of mutual influences between the works of Garfinkel and Goffman is provided by Rawls 2010 .

10. Elsewhere, Goffman observes that: "participation in any contact with others is a commitment [...] an involvement in the face of others that is as immediate and spontaneous as the involvement he has in his own face" (1967: 6).

11. While most interpreters tend to emphasise the constraining power of face work (e.g. Gamson 1985), it is important to note also its constitutive role in the production of the social bond, by putting social interaction and mutual interdependence at the very root of social situation. Even if we grant that "his first lesson is that all face-to-face interactions operate to restrain challenge" (Gamson 1985: 610), we should also consider that face-to-face interactions operate in a way that presupposes and instantiates a deeply reciprocal form of social interaction based upon mutual accountability and shared responsibility for the successful furtherance of social life in the face of its intrinsic and irreducible vulnerability. Constraining power, vulnerability, and mutual interdependence are, therefore, three distinct but inseparable dimensions of the normative constitution of ordinary life, according to Goffman.

12. This is, in a certain sense, no surprise, as pragmatism, via G. H. Mead's social psychology, the Chicago School of sociology, and symbolic interactionism, has had an enduring influence upon the sociological traditions here evoked. See Collins 1989.

13. The expression is Laugier's, who employs it in an insightful article exploring the connections between Austin's and Goffman's approaches to the ordinary. My reading of Austin is heavily indebted to Laugier's interpretation in Laugier 2009, and Laugier 2012.

14. See Rawls 2006 for an assessment of Garfinkel's positioning with reference to pragmatism and symbolic interactionism. See Collins 1989, Emirbayer 2010, and Quéré 2011 for a more positive appreciation. Among the rare philosophers having explored the philosophical implications of these approaches, it is notably within critical theory that the work of Garfinkel and Goffman have had some influence. See in particular Habermas 1984, McCarthy 1996, and Celikates 2009.

15. Recent discussions of habit in the pragmatist tradition include Hartmann 2003, Kilpinen 2012, and Sullivan 2006. See Camic 1986 for a historical appraisal of the place of the notion of habit in sociology with reference to the pragmatist tradition and Schubert 2011 for a similar reading of the notion of creativity. Joas 1996 is the standard reference for the analysis of creativity as a central category of a pragmatist theory of action.

16. This also applies to reasons for action, see Brandom (1994: 229-42).

17. This vocabulary was introduced by Will in a series of articles published between 1981 and 1993. Will's most relevant contributions to normative theory have been collected in Will 1997. For a presentation of Will's philosophical trajectory, see the editor's introduction to that volume. For an examination of Will's theory of normativity, see Frega 2013. 


\section{ABSTRACTS}

This paper aims to develop a new understanding of normativity based upon the priority of the ordinary. By relying upon diverse sociological and philosophical traditions, the paper seeks to emphasize the ordinary tacit assumptions which provide the basic structure of our experience of the world and its normative features. The general argument is that, whereas sociological traditions of social interactionism shed new light upon the "empirical fact of normativity", ordinary language philosophy and pragmatism offer a theoretical account of normativity which is consistent with the picture of normativity which emerges out of these empirical descriptions. The paper synthesizes the main achievements of these traditions into a unified account of normativity.

\section{AUTHOR}

\section{ROBERTO FREGA}

IMM-CNRS, Paris

fregarob[at]gmail.com 